\title{
Avoimen tieteen viikko Liègen yliopistossa - Mitä opittiin?
}

\author{
Marja-Leena Harjuniemi, Minna Marjamaa ja Katri Rintamäki
}

\begin{abstract}
Belgialainen Liègen (ULg) yliopistokirjasto järjesti jo kolmannen kerran Open access -aiheisen Erasmus-viikon korkeakouluhenkilöstölle. Ohjelma oli rakennettu niin Liègen yliopiston kirjaston asiantuntijoiden kuin osallistujien esityksistä. Esitysten aiheina oli mm. avoin julkiseminen, tekijänoikeudet, aineistonhallinta, avoimen tieteen työkalut ja palvelut. Mitä viikosta jäi käteen suomalaisille osallistujille?
\end{abstract}

$\mathbf{O}_{\text {pen access -ohjelmaan osallistui } 20 \text { kirjastolaista }}$ 11 yliopistokirjastosta Alankomaista, Isossa-Britanniasta, Liettuasta, Maltalta, Puolasta, Ranskasta, Romaniasta, Saksasta, Suomessa, Sveitsistä ja Tsekistä. Teemaryhmän kokoonpano oli onnistunut: pienten ja suurten maiden, yksityisten ja valtionyliopistojen laaja kirjo toi havainnollisesti esille toimintaympäristöjen erilaisuuden. Eroavaisuuksia vahvemmin esille nousi kuitenkin avoimen tieteen tematiikan globaalisuus: samat tutkimustoiminnan arvioinnin ja rahoituksen, tieteellisen julkaiseminen ja avoimen tieteen kysymykset olivat ajankohtaisia.

\section{Liègen malli eli Liègen yliopiston kirjaston avoimen tieteen palvelut}

Liègen yliopiston kirjaston visiossa yhdistyvät yliopiston historia ja nykyisyys. Kirjaston visiona on:

1. kulttuuriperinnön säilyttäminen

2. tiedon saatavuuden edistäminen

3. tieteellisen tiedon tuottamisen ja jakamisen tukeminen.

Kulttuuriperinnön säilyttämiseen kuuluu seuraava palvelupaketti:

- DONum - Dépôt d'Objets Numérisés -julkaisuarkistoon digitoidaan kirjaston harvinaisia historiallisia kokoelmia

- ORBi (Open Repository and Bibliography) -julkaisuarkistoon rinnakkaistallennetaan yliopiston tutkijoiden julkaisut ja se sisältää yliopis- ton julkaisubibliografian

- Matheo (Master Thesis Online) -arkistoon tallennetaan yliopiston pro gradu -tutkielmat

- PoPuPS (Portail de Publication de Périodiques Scientifiques) -portaalissa julkaistaan Liègen yliopiston tutkijoiden toimittamat aikakauslehdet avoimesti saataviksi ja parannetaan siten tutkimusjulkaisujen näkyvyyttä

- URBi (University Repository of Bibliographies) -työkalun avulla tutkijat voivat laatia ja jakaa akateemisen CV:nsä.

Marraskuussa 2008 lanseeratun ORBin pohjana on vuonna 2007 laadittu ja vuonna 2015 päivitetty yliopiston julkaisupolitiikka, ULg mandate, jonka lähtökohtana on yliopiston julkaisujen näkyvyyden, saatavuuden ja vaikuttavuuden edistäminen.

Tiedon saatavuuden edistämiseen sisältyvät mm. kirjaston infrastruktuurin, kuten luku- ja ryhmätyötilojen sekä verkkopalvelujen ylläpitäminen; kirjaston koulutus- ja tukipalvelut; sekä kirjaston rooli yliopistoyhteisössä aktiivisena avoimen tieteen tukijana. Kirjaston infrastruktuurissa digitaaliset palvelut ovat merkittäviä, sillä peräti 3/4 kirjastoaineistoista tarjotaan digitaalisina. Myös kirjaston e-palveluissa korostetaan vahvasti avointa julkaisemista: lehdistä $64 \%$ ja kirjoista peräti $89 \%$ on open access -julkaisuja.

Tieteellisen tiedon tuottamisen ja jakamisen tukeminen tarkoittaa sekä Liègen yliopiston kirjaston osallistumista tiedeviestintään että laadunar- 
viointia $\mathrm{mm}$. bibliografisten tiedon ja bibliometristen analyysien kautta. Liègen yliopiston kirjasto on sitoutunut edistämään avoimen julkaisemisen mallia sekä tiedottamaan hybridijulkaisemisen ja saalistajakustantajien aiheuttamista turhista kustannuksista yliopistoille. Liègen yliopiston avoimuuden politiikan lähtökohta on avoin tiede kiinteänä osana julkaisemisen ja arvioinnin prosessia, ei vain vaihtoehtona suurten kustantamoiden Publish or perish -ajattelulle. Liègen yliopiston avoimen tieteen ja tutkimuksen politiikkaa sovelletaan koko Belgian ranskankielisessä tiedeyhteisössä ns. Liègen mallina.

\section{ULiège ORBi = "OK! We'll do it!"}

Viikon aluksi Liègen yliopiston entinen rehtori, Bernard Rentier, kertoi ULg:n matkan yhdeksi maailman menestyneimmistä OA-suunnannäyttäjistä. ULiègen ORBi-arkisto perustettiin vuonna 2007 nimenomaan silloisen rehtori Rentierin toimesta.

"I was convinced about OA", sanoi Rentier ja kertoi pari hauskaa anekdoottia siitä, kuinka marssi itse paikalle, jos joku yritti livetä sovitusta linjasta lähettämällä järjestelmään artikkelin sijasta pelkän tyhjän lomakkeen. "What the Hell?? PDF with nothing?? This is ridiculous!".

Hän painottikin, että tiukka linja ja johtajuus ovat OA-linjausten luomisessa aluksi tarpeen. Muuten (kuten Suomessakin on todettu) "kaikki pitävät asiaa hyvänä, mutta kukaan ei sitä tee”.

\section{Tiukka mandaatti}

ULg:ssä otettiin heti alussa tiukka linja: jos tutkimusta ei ole tallennettu ORBiin, sitä ei ole olemassa arvioinneissa. On huomattavaa, että päätös tehtiin jo vuonna 2006, kahdeksan vuotta ennen saman periaatteen omaksunutta Britannian ensimmäistä REF:iä.

Tutkijat tallentavat tiedot julkaisuistaan itse. He myös merkitsevät esim. embargo-ajat, julkaisun mahdolliset rahoitustiedot sekä versiotiedot itse. Järjestelmään on pakko tallentaa myös liite. Ohjelma ei anna tallentaa tietoja, ellei myös var- sinaista artikkelia ole lisätty.

Merkillepantavaa siis, että ULg:n linjauspakko koskee vain tallentamista, ei avoimeksi laittamista. Riittää, että tiedoston tallentaa, vaikka ei avaisikaan pääsyä siihen. (ORBi ei siten ole niin avoin arkisto kuin mitä asiayhteys antaisi olettaa.)

\section{Vastuu tekijöillä}

Toisin kuin meillä Suomessa ULg:ssä pidettiin tärkeänä, että tutkija tekee julkaisuarkistotallennukset nimenomaan itse open access -liikkeen alkuperäisen idean mukaisesti. "Authors will have to do the job", painotti Dominique Chalono. Järjestelmään tallennetut tiedot ovat tutkijan itsensä vastuulla. Jos tutkija tallentaa, vaikka kustantaja sen nimenomaan kieltää, on vastuu tallentajalla. Samoin jos tekijä merkitsee julkaisun vertaisarvioiduksi, vaikka ei ole, on vastuu tekijällä.

Kirjasto tarkistaa tallennettuja tietoja, mutta vain ylimalkaisesti. Eikö ULg:ssa koeta ongelmaksi, että ORBissa on osin myös vääriä tietoja? Dominique vastasi toistaen: "Vastuu on tekijällä."

Kirjaston ORBi-tiimin rooli prosessissa onkin pääsääntöisesti vain lisätä tietoisuutta ja ohjeistaa. Tiimiläiset vastaavat tutkijoiden kysymyksiin (joita on paljon) ja keskittyvät ORBi-infrastruktuurin kehittämiseen ja uusia työkalujen haltuun ottamiseen varsinaista tarkistustyötä enemmän. ORBi-tiimiin kuuluu 2 kirjastonhoitajaa, 1 projektin johtaja sekä 2 IT-ammattilaista.

\section{Tutkijat tyytyväisiä}

Nyt kymmenen toimintavuoden jälkeen tulokset ovat hyviä. Yli 90 \% ULg:n tutkimuksesta on tallennettu ORBi-arkistoon. Tästä $90 \%$ :sta noin $35 \%$ on avoimesti saatavissa. Rajattua aineistoa varten käytössä on Request a copy -toiminto, jolla embargon tai käyttäjätunnuksen takana olevia julkaisuja voi pyytää suoraan tekijältä.

Myös tutkijoiden tyytyväisyyttä ORBiin on tutkittu. Tutkijat ovat saaneet ORBin ansiosta työ- ja yhteistyötarjouksia sekä yhteydenottoja yrityksiltä. He ovat huomanneet, että tallennus todellakin kannattaa ja että ORBi on olen- 
nainen työkalu osana heidän omaa menestystään tutkijoina.

ORBi on tuonut näkyvyyttä koko yliopistolle ja palvelu onkin äänestetty ULg:n kaikista järjestelmistä tutkijoille merkityksellisimmäksi. Alun johtajavetoinen top down -vaatimus on muuttunut tutkijoista itsestään kumpuavaksi bottom up -aktiivisuudeksi. Tutkijat haluavat saada tutkimuksensa ORBiin ja näkyville.

\section{ORBin kootut neuvot}

- Hanki mandaatti. Älä kuitenkaan käytä mandaattia argumenttina. Korosta hyötyjä. Kerro, mitä hyvää ja omaa asemaa edistävää tutkija tallentamisesta itselleen saa.

- Vetoa mandaattiin vasta viimeisenä keinona.

- Tee arkistosta välttämättömyys. Osoita, että arkistolla on ratkaiseva merkitys siinä, miten julkaisu - ja tutkija itse - menestyy.

- Ota yhteyttä suoraan tutkijoihin. Anna ohjeet oikeaan aikaan ja oikeassa kontekstissa. Pelkät yleiset infot eivät riitä.

- Auta tutkijoita näkemään tulokset: Google-näkyvyys, visuaaliset tilastot (pylväät, käyrät), latausmäärien kasvu, viittausmäärien kasvu.

- Ja ennen kaikkea: tee asiasta helppo. Mitä helpompi tallennusprosessi on, sitä enemmän tallennuksia. Aloita heti. tisesti OA-maailman ei niin toivotuista ilmiöistä. Hybridilehdet ovat tilausmaksullisia lehtiä, joista APC-maksun (Article Processing Cost) maksamalla voi ostaa yksittäisiä artikkeleita avoimeksi. Thirion rinnasti hybridit suoranaisen haitallisiksi: hybrid $=$ racket $\neq \neq O A$. Muut OA-mallit hän määritteli termein 'reilu' ja 'epäreilu' pitäen perusteena OA-kustannusten määrää. Epäreilun puolelle Thirionin mielestä menee, jos APC ylittää $500 €$.

Koko Belgian ranskankielinen tiedeyhteisö onkin ottanut hybrideihin tiukan kielteisen kannan: Hybridilehtiä ei suosita eikä niiden APCmaksuissa auteta. Myös Belgian flaaminkielinen yhteisö suosii vihreää väylää. Liittovaltion tasolla vaatimukset ovat kuitenkin Golden OA -tasoa.

Myös muiden osallistujien esityksistä kävi ilmi, että käytäntöjen kirjo on laaja ja ristiriitainen. Osa tahoista kehottaa käyttämään kultaista väylää, tukee jopa APC-maksuissa. Osa taas ei hyväksy mahdollista maksullisuutta ollenkaan. Keskustelu on kärjistynyt etenkin Britanniassa, jossa maan johtavien tiedetahojen (HEFCE; Research Council UK; REF) linjaukset lähes poikkeuksetta ovat keskenään ristiriitaisia. Samaan tutkimukseen voi siis kohdistua useampi, keskenään ristiriitainen vaatimus niin, että tutkijan on mahdoton pysyä perässä - saati noudattaa niistä jokais-

\section{Fools or Fair? \\ Reilun avoimuuden raja}

Mikä sitten on paras tapa toteuttaa avoimuutta: Maksuton julkaisuarkistojen vihreä vaihtoehto, jossa rasitteena ovat embargot ja versiot - vai maksullinen kultainen tie, joka sallii välittömän avoimuuden ja kustantajan viimeisen version käytön? Entä hybridilehdet - tukeako niiden APC-maksuissa vai ei? Eri maissa ja organisaatioissa on keskenään ristiriitaisia suosituksia.

ULg:n PaulThirion puhui kriit-

\section{Hybrid $=$ Racket $\neq$ OA}

Lesson 1 for (profit) publisher : How to maximize profit

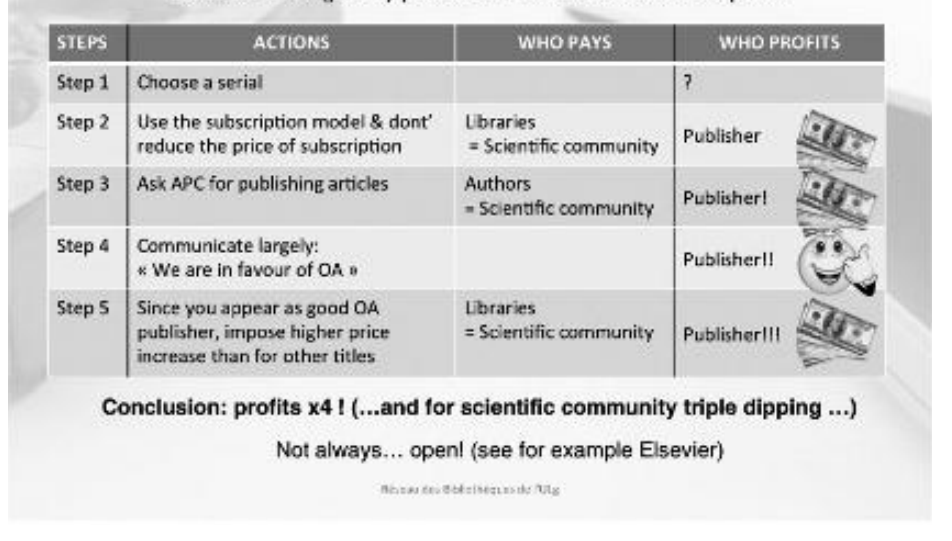

(Paul Thirion, ULg: What about Gold OA?) 
ta. Lontoon SOAS Universityn Helen Porter lainasi osuvasti esityksessään Bill Hubbardin (2015) aiemmin tekemää kuvaa kertoessaan brittiläisen tutkijan sekavasta arjesta.

\section{SCOAP3-mallissa paljon hallinnollisia kustannuksia}

Ongelmattomina Thirion ei pitänyt myöskään konsortioihin perustuvia malleja. Esimerkiksi hän otti fysiikan alan OA-lehtikonsortion eli
SCOAP3-mallin. Konsortioon kuuluu 3000 kirjaston ja tutkimusorganisaation 47 maasta, päävetäjänä toimii CERN.

SCOAP3-mallissa kymmenkunta fysiikan alan keskeisintä julkaisua muutettiin 2014 OA-lehdiksi. Konsortioon kuuluvat organisaatiot maksavat kustantajalle tietyn summan/artikkeli vuosittain, keskimääräinen APC on $1000 € /$ artikkeli. SCOAP3-mallin ongelmana on mittavat hallinnolliset ja piilokustannukset: suuresta osallistujamäärästä johtuen taustaneuvottelut ovat raskaat ja osallistumiskulut tulevat kalliiksi. Lisäksi yksistään CERNin panostus hankkeeseen on ollut mittava (2-3 hlöä; 1.2 M€ for Phase 1; 3,6 for Phase 2). Belgian näkökulmasta SCOAP3malli on kaksi kertaa kalliimpi kuin mitä Belgiassa samoille lehdille aiemmin maksetut tilausmaksut olivat. Hankkeen järkevyys on Thirionin mielestä kyseenalainen myös siksi, että valtaosa artikkeleista on ArXiv-arkiston kautta joka tapauksessa avoimesti saatavissa.

Thirionin nosto oli tervePredatory publishers...

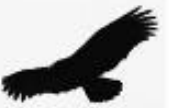

A "paper" submited to International Journol of Advanced Computer Technology

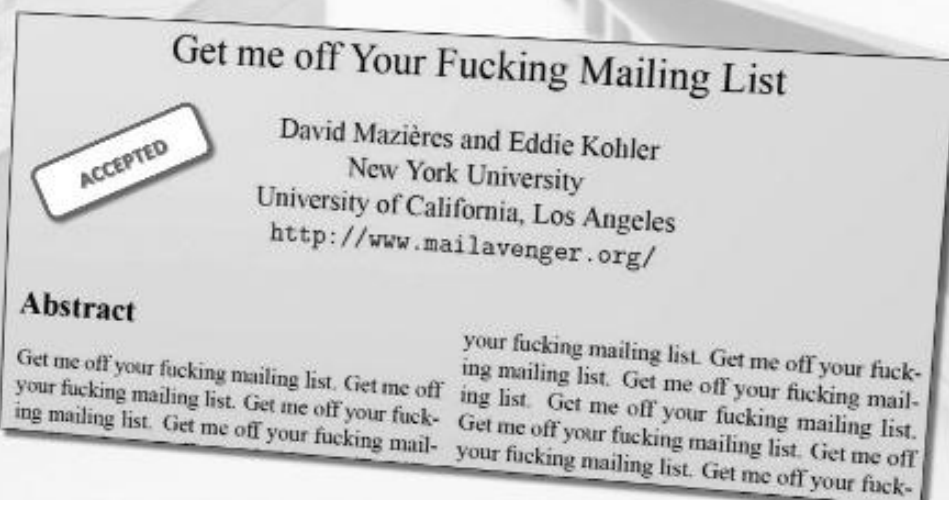

(Paul Thirion, ULg: What about Gold OA?) tullut: OA-keskustelu huomioi yleensä vain APC-maksut. Vähemmälle keskustelulle jää se, kuinka paljon resursseja kuluu sekaviin ohjeistuksiin, heppoisiin suosituksiin ja järjestelmiin OA:n taustalla.

\section{Saalistajalehtien tunnusmerkit}

Paitsi epäselvät toimintamallit, tutkijoiden harmina OA-maailmassa ovat myös ns. saalistajalehdet (predatory journals). Tsekkiläinen Jiri Kratochvil (Masaryk Univeristy) oli ko- 
keilumielessä lähettänyt saalistajalehdeksi epäilemäänsä lehteen itse keksimänsä tutkijaprofiilin ja ilmaissut näin halukkuutensa päästä lehden toimituskunnan jäseneksi. Ja eipä aikaakaan, niin tämä Dr. Joseph Albus Švejk, keksitty hahmo, löytyi listattuna kyseisen lehden toimituskunnan jäsenistöön.

Paul Thirion puolestaan kertoi esimerkin tapauksesta, jossa tutkija oli kyllästynyt saalistajalehden jatkuvaan sähköpostipommitukseen ja lähettä-

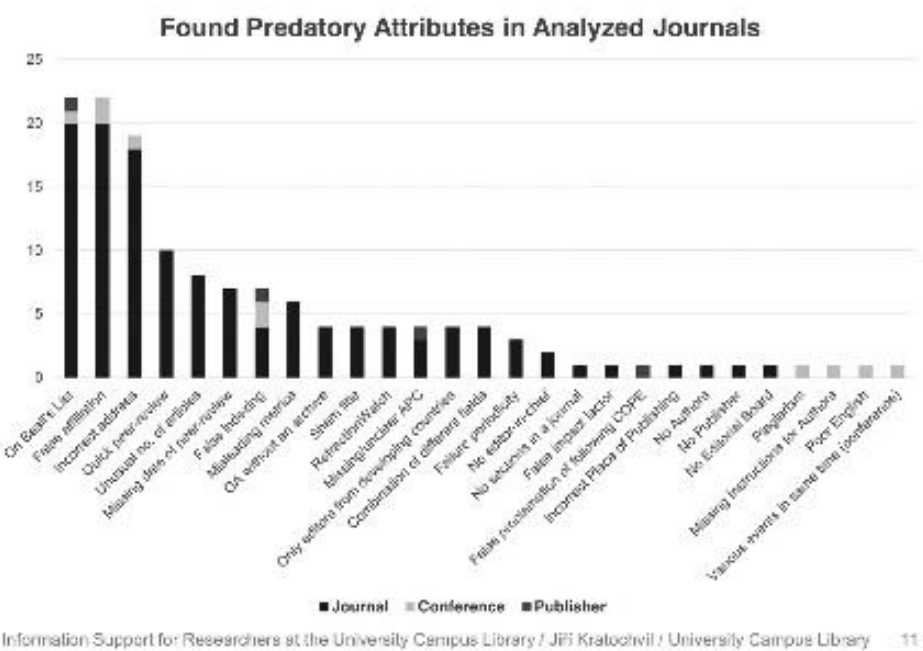

(Jiri Kratochvil, Manyar University: Support to researchers at the University Campus Library)

nyt lehden julkaisuprosessiin

täysin roskaa sisältäneen artikkelin otsikolla Get me off Your Fucking Mailing List. Tuloksena oli: ACCEPTED. Kyseinen käsikirjoitus oli siis tullut muitta mutkitta hyväksytyksi kyseiseen lehteen.

Näiden esimerkkien valossa ymmärtää, että uudenlaiset OA-markkinat edellyttävät huolellista varovaisuutta ja kykyä julkaisukanavan kriittiseen valintaan. Masaryk Universityn tutkijoilleen tekemä indikaattorilista onkin tervetullut työkalu avuksi tunnistaa $\mathrm{OA}$-alan epäterveet toimijat.

\section{Tulevaisuutta: Entä jos kustantajat ostavat OA-markkinat?}

OA-maailman uudet teemat liittyvät vahvasti dataan ja sen avoimeksi saamiseen. Myös avoin vertaisarviointi ja uudet työkalut, esim. ORCID ja sen tuomat mahdollisuudet, puhuttavat.

Kuitenkin kaikkein kiinnostavimman tulevaisuuden skenaarion esitti Dominique Chalono, joka esitti kysymyksen: Miten käy, jos kustantajat hankkivat monopolin OA-markkinoilla? Kysymys on hätkähdyttävä, mutta relevantti. Esimerkkejä tästä jo on. Aiemmin puhtaasti non profit -pohjaisia alustoja on myyty ja kustantajien omien OA-mallien asema vahva.

\section{Mitä opittiin?}

Viikosta jäi käteen kolme asiaa. Ensimmäisenä se, että mandaatti ja policy muodostavat toiminnan perustan, mutta tärkeintä on tehdä mallista tutkijalle merkityksellistä: Liègen yliopisto ja Britannian REF ovat sitoneet avoimuuden arvioinnin edellytykseksi - näin avoimuudesta on tullut tutkijan työn elinehto. Toisaalta Suomessa yleistyvässä mallissa tehdään tutkijalle mahdollisimman paljon valmiiksi eli kun rinnakkaistallentamiseen ei tarvitse nähdä vaivaa, on helppo nähdä avoimen toiminnan edut.

Toinen mieleen jäänyt asia on se, että avoimuutta voi toteuttaa eri tavoin: Suomessa yhä useampi yliopistokirjasto tekee rinnakkaistallennukset tutkijan puolesta; Liègessä sen sijaan tutkija tallentaa itse, kirjasto ei tarkista tallennuksia eikä virheitä oteta yhtä vakavasti kuin Suomessa. Dominique Chalonon kommentti kuvaa hyvin asenne-eroavuuksia: "There's been no charges against the University yet anywhere".

Kolmas opittu asia on, kuinka samoja haasteita kysymyksiä ratkotaan joka päivä ympäri Eurooppaa. Erityisestiaineistonhallinnassa ollaan suurimmassa osassa korkeakouluja käynnistysvaiheessa. 
Viikon aikana yhteistyön merkitys tuli konkreettisesti esiin niin kansallisella kuin kansainvälisellä tasolla.

\section{Lopuksi}

Liègen yliopisto ansaitsi suuret kiitokset henkilövaihdon sujuvista tapahtumajärjestelyistä, keskustelevasta työskentelymuodoista, hyvästä ilmapiiristä ja ennen kaikkea asiantuntevista asiantuntija-alustuksista. Liègen kaupunkia ja yliopistoa voi suositella niin Erasmus Staff Training Week -kohdetta kuin henkilökohtaista opetus- tai henkilövaihtokohdetta etsiville.

\section{Lähteet ja lisätietoa}

Laureys, Eric (2017). Belgium and European Framework. http://lib.ulg.ac.be/sites/default/files/08-laureys_ open_access_in_belgium_in_international_perspective.pdf

Open Access Belgium - Promoting Open Science https://openaccess.be/

Paquot, François (2017). Urbi. http://lib.ulg.ac.be/sites/default/files/09-presentation_170509_urbi_erasmusweek.pdf
Thirion, Paul (2017). General presentation of the ULg Library \& OA Mandate. http://lib.ulg.ac.be/sites/default/files/08-thirion_ulg_library-oa_at_ulg_erasmus_week_may_2017.pdf

University of Liège [2017]. ORBi - Open Repository and Bibliography: ULg mandate http://orbi.ulg.ac.be/ project?locale $=$ en $\&$ id $=103 \#$ oblig

University of Liège [2017]. PoPuPS - Portail de Publication de Périodiques Scientifiques http://popups.ulg. ac.be/index.php?lang=en

\section{Tietoa kirjoittajista:}

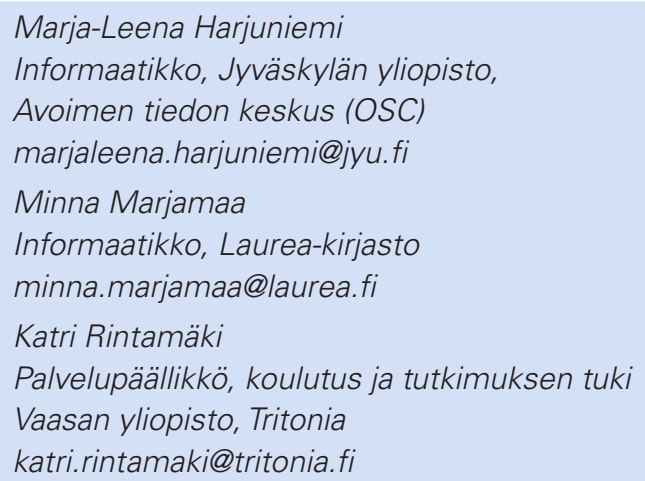

